\title{
Factors determining land use and transportation planning achievement in developing countries
}

\author{
Y. A. Shamsul Harumain \& A. Morimoto \\ Graduate School of Engineering, Utsunomiya University, Japan
}

\begin{abstract}
Just like the chicken and egg situation, the relationship between land use and transportation and its influences on each other is challenging to justify, especially in developing countries. One of the main reasons was because developing countries strive hard in economy improvement, thus land use and the future of transportation planning becomes unclear. The enthusiasm to increase economy growth and to move forward to become a highly developed country affecting developing countries to be biased over the importance of ensuring proper land use and transportation planning. However, achievement in economy is not a golden ticket to ensure the success of land use and transportation planning in developing countries. Although this theory seems generic, the difficulty to solving land use and transportation problems is not clear as there are diverse characteristics of a developing country within itself. In this research, we found that the economy factor is not the only factor in determining the success of land use and transportation planning but there are more factors involved. This can be caused by diverse reasons such as the independence period. The independence period of a developing country contribute to the diverse historical background of a developing country and it also has determined factors of achievement in land use and transportation planning. Based on the analysis result, we found that the independence period provides differences in the relations between factors in developing country land use and transportation planning.
\end{abstract}

Keywords: land use transport integration, urban planning, developing countries. 


\section{Introduction}

Typically, world are judged by economy and development growth rate. Developed countries as they say, are countries generally controlling the world economy and also advanced in land use and transportation planning. These countries are also considered matured in the field of land use and transportation. In the fundamental land rent theory, development demand in city centre acquires land space has increased land price thus forced outer city lands to develop and encouraged work-home travelling. Therefore, economy factor is a great influence to developing countries not only in developing land but as well as its influence to the travelling pattern. In addition, traffic nodes are highly concentrated with commercial activities in city centre and most residential located outside concentrated areas due to lower land price. Hence, the pattern of land use influenced the pattern of travelling and transportation planning. In China alone, the numbers of civil motor vehicles has rise from 3.2 million in 1985 to 31.59 million in 2005 (Deng [1]). Sarma [2] mentioned Bangladesh urban planning problem is generally caused by government failure to control it. Just like chicken and egg situation, the relationship between land use and transportation planning in developing countries are challenging to put in plain words. In this research, we establish that there are more factors involved in determined the failure of land use and transportation planning adding to the economy factor. As explained in Figure 1, the relationship between land use and transportation planning in developing countries can be described from the idea of demand and supply concept.

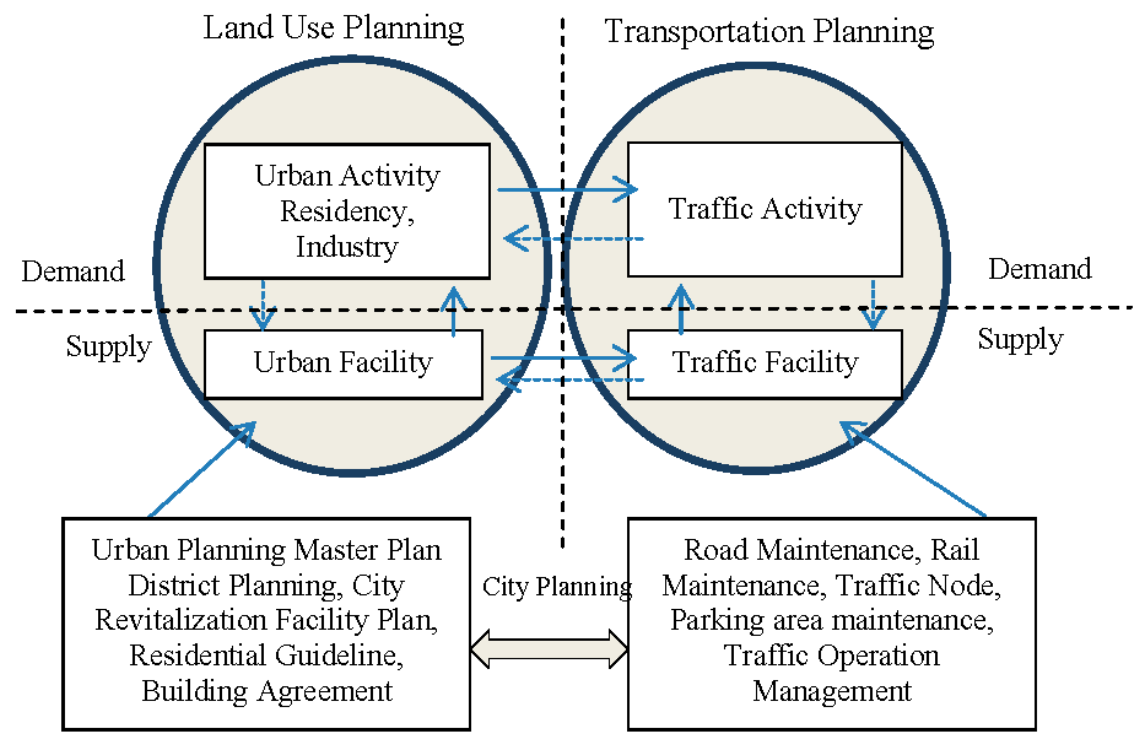

Figure 1: $\quad$ The relationship between land use and transportation planning. 
Based on figure 1, urban facility represents as supplier for growth of urban activity for example a residential and commercial development while traffic facilities are highways and roads facilitating traffic activity. Urban facility is commonly prepared by the government and private developers also contributed towards urban facility in the land development. The increase supply of urban facility resulted increase in urban activity and increasing demand for more economy activity. As economy activity gets rapid, traffic activity also gets higher in demand. The high traffic activity also increases urban activity in the city however poor demand by traffic facility resulted problems like traffic congestions. The cycle relationship between land use and transportation existed when traffic activity increase it attracts urban activity to increase in demands as well. The success of land use and transportation planning is based on the good balance between urban facility and traffic facility. The failure of the government in most cases to supply efficient traffic facility and also provided efficient master plan for urban facility resulted failure in the balance between land use and transportation planning.

Land use planning in developing countries is influenced by many factors and usually urban planners and transportation planners missed the mark to balance each other. According to Rodrigue et al. [3], the government are most involved in the policy process and their role is vital in land use and transportation planning. Moreover, Iyer [4] identified that the poorest 20 countries was also colonized. Therefore, colonization can possibly caused developing countries deprived in land use and transportation planning. Tiwari [5] identified that the transport and land use in the South Asia cities are different from the West. The nature of development and transportation background is different from the Western countries. Although many technology and knowledge advancement are from developed countries, Nag et al. [6] mentioned one of many reason for the shift of production from developed to developing countries occurs because of profit and low labour cost for example in automobile industries. The economy needs in developing countries surmount the needs to establish success in land use and transportation planning. Although there are progressively effort to make land use and transportation planning success, the high and unregulated growth of land use exceeded the limitation of traffic facility resulted failure in land use and transportation planning. Development pressure became prior to progress in economy development. Furthermore, developing countries economy stability is not an insurance to achieve success in land use and transportation planning. There are many reasons involved and each of developing countries is different from each other. Therefore, the goal of this research is to investigate what are other factors involved in the failure of land use and transportation planning and how can it be difference among developing countries itself.

\section{Objective}

Developing countries are very unique and they owned diversifying characteristic and background. This includes in economic, political, social, religion, cultural and many more. The understanding towards history of a country enables urban 
planners and transportation planners to plan for better future. The Malaysian urban and regional planning in the beginning is a blueprint of the British town planning. After independence in 1957, transition take into progress from the colonial period to an independence government system and adaptation process is not always easy. In contrast, although developing country like China did not suffer from colonization biased like Malaysia, the land use and transportation planning problems are caused by weak enforcement and its planning system. In addition, the weak enforcement of policy by the government, excessive conversion of agriculture land, long work-home commuting and the weakness in policy are some factors resulting failure in land use and transportation planning in China $[7,8]$. The lack of adaptation skills and also know-how to plan over proper land use and transportation planning causes problem in China. Hence, we can understand that there are many reasons affecting the achievement of land use and transportation in developing countries. So, it is significant to investigate factors determining land use and transportation achievement in developing countries. Therefore, the objectives of this study are:

1. To investigate the factors that had failed land use and transportation planning in developing countries.

2. To examine the influence of independence period to the problems in land use and transportation planning in developing countries.

\section{Methodology}

In order to execute and established the objective of this study, we implement supportive methods. The first objective of this study is to investigate factors failed land use and transportation planning in developing countries. This is conducted by analysing respondent data of surveys from 1999 until 2012. All of our respondents are professionals in land use and transportation planning. The professionals are gathered in a Japan International Cooperation Agency (JICA) program and the numbers of respondent are about 231 professionals from 55 developing countries. Professionals and researchers in Japan are invited to give lecture regarding land use and transportation planning to all participants in the program. At the end of the program, we take advantage to distributed questionnaires and gathered data from the participants. Data investigation also includes background of the respondent, country of origin and the name of colonizer if any. Using KH Coder, we extract the words from the respondent comments. This is to recognize factors of failure in land use and transportation through extruding frequent words and developing word links. KH Coder is an analysis tools for text data mining and it is able to perform the co-occurrence network. In this method, the software extracts word to represents 10 frequent words for land use and transportation planning failure. In order to achieve the first objective, we separated the data into two groups that is from 1999 to 2006 and the other group is from 2007 to 2012. The second objective is achieved by studying all respondent countries independence year. Respondents are also divided into two groups that are developing countries with independence year 
below 65 years and another group is independence year of 66 years and above based on World War 2 period as point of reference. This is to understand whether a country needs more time to plan for land use and transportation. Developing countries that gain independence before World War 2 are considered countries that produce land use planning first hand before any interruption of transportation planning. Whilst, the second group of developing countries below 65 years of independence are countries that produce their land use planning along with the development of automobile development especially in the 1970 to 1980s. This is to understand the influence of independence period and the needs of ample development period towards land use and transportation planning.

\section{Research findings and analysis}

All of the respondents in this survey are professionals of land use and transportation planning in developing countries. Using the $\mathrm{KH}$ coder software, we obtained the word frequency list of the whole data. In order to achieve the first objective, words are extracted from respondent comments about land use and transportation planning failure in their country. The data are separated into two groups that are frequent words between 1999 until 2006 and frequent words between 2007 until 2012. This is to understand the implication of world economy crisis in 2007 towards the reason of land use and transportation planning failure in developing country. Based on Table 1 below, the word government is the most frequent words found in the frequency list. Respondent in 1999 until 2006 suggest 56 words of government while in 2007 until 2012 there are 25 words of government. After 2006 the word budget and politician can be seen in the 2007 until 2012 columns but not before 2007. Hence, suggests to us that the financial reasons are not so obvious before the world economy crisis.

Table 1: $\quad$ Frequency of 10 highest words from the respondent answers.

\begin{tabular}{|c|c|c|}
\hline Year (number of words) & $1999-2006$ & 2007-2012 \\
\hline \multirow{10}{*}{$\begin{array}{l}\text { Most frequent words } \\
\text { represents factor of failure } \\
\text { in land use and } \\
\text { transportation planning in } \\
\text { developing countries. }\end{array}$} & Government (56) & Government (25) \\
\hline & Ministry (47) & Development (24) \\
\hline & Regulation (43) & People (20) \\
\hline & Development (39) & Ministry (18) \\
\hline & Master (39) & Policy (18) \\
\hline & Law (33) & Budget (17) \\
\hline & Policy (27) & Coordination (17) \\
\hline & People (26) & Law (17) \\
\hline & Traffic (26) & Master (14) \\
\hline & Implementation (25) & Politician (14) \\
\hline
\end{tabular}

From the initial analysis, we can recognize that the failure is very much related to the government, formulation of regulation, the rapid development and the implementation. Hence, it is comprehensible that the level of land use and transportation is fragile to the government organization and their goal in land use 
and transportation planning. Further analysis enable us to understand deeper the situation of land use and transportation planning in developing countries.

\subsection{Further analysis}

The second objective of this analysis is to examine the influence of independence period to the failure in land use and transportation planning in developing countries. Initially, we separate respondents' country of origin based on their independence period. After that, we will perform the co-occurrence network analysis in each group and analyze the results. All respondents' countries of origin are listed in Table 2 based on the country independence period since 1945.

Table 2: $\quad$ Developing countries’' independence period since 1945.

\begin{tabular}{|l|l|l|l|l|l|}
\hline \multicolumn{3}{|c|}{$\begin{array}{c}\text { Below 65 years } \\
\text { (29 developing countries) }\end{array}$} & \multicolumn{3}{c|}{$\begin{array}{c}\text { 66 years and above } \\
\text { (26 developing countries) }\end{array}$} \\
\hline Algeria & Tunisia & Tanzania & Ethiopia & Panama & Jordan \\
\hline Cambodia & Uganda & China & Albania & Paraguay & Mexico \\
\hline Cameroon & Bahrain & Myanmar & Bhutan & Peru & Mongolia \\
\hline Egypt & Bangladesh & Laos & Bolivia & Philippines & Vietnam \\
\hline Ghana & Kenya & India & Brazil & Saudi Arabia & Nepal \\
\hline Jamaica & Malawi & Pakistan & Bulgaria & Syria & Nicaragua \\
\hline Malaysia & Mauritius & Zimbabwe & Chile & Thailand & Haiti \\
\hline Rwanda & Zambia & Yugoslavia & Colombia & Turkey & Indonesia \\
\hline Senegal & Mozambique & Palestine & Guatemala & Venezuela & \\
\hline Sri Lanka & Romania & & & & \\
\hline
\end{tabular}

Based on our analysis as stated in Table 2 shows there are 29 developing countries categorized under developing countries with below 65 years of independence. On the right side of Table 2 are 26 developing countries with more than 66 years of independence. $\mathrm{KH}$ Coder software is also used in this analysis to understand the influence of independence period towards failure in land use and transportation planning. All respondents' answers are converted from text to networks through co-occurrence network based on each independence period group. The co-occurrence network will convert the respondents answer on failure of land use and transportation planning in their country based on relationship between the words. After that, the diagrams are evaluated based on nodes centrality and one of the method is based on degree of centrality. Based on degree of centrality, we can understand the number of links that a node has between the words. This is created on the number of ties associated to each other and creates a form of popularity. This represent through colour code ranging from dark purple, light purple, pink, white, light blue and blue. The ranges of colour represent word strength of the index in the degree of centrality. The high index will turn to dark purple and larger nodes represent higher frequency words. Referring to both result analysis below (figures 2 and 3), the word "government" represent as a large nodes that illustrate the high 
frequency of words in land use and transportation planning failure. The result of analysis as shown in figure 2, word such as policy, budget, people, law, knowledge and leadership are highlighted in the diagram. In the diagram, $\mathrm{KH}$ Coder co-occurrence network (links) analysis existed between government and policy, leadership and commitment, people and knowledge, law and knowledge. People and knowledge is link thus suggests to us the level of knowledge among people about land use and transportation planning contributed to its failure. Larger nodes means higher frequency of words and thicker lines means stronger edges. Below is figure 2 containing words suggesting failure of land use and transportation planning in developing countries with below 65 years of independence.

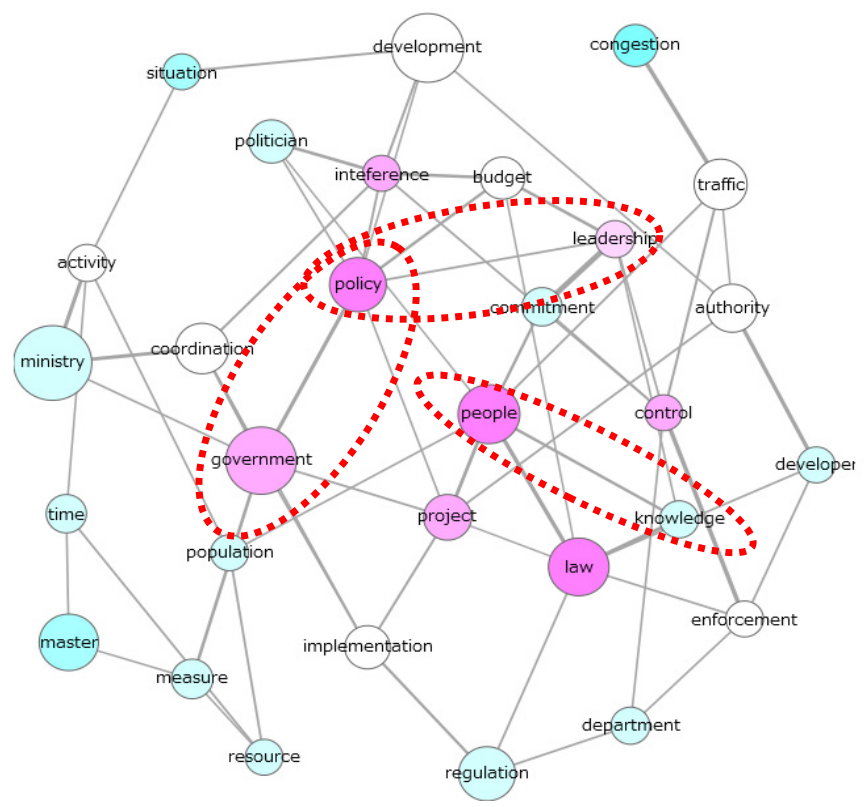

Degree of Centrality Index

$<$ High $\square \square \square \square \square \square$ Low $>$

Figure 2: Developing countries with independence below 65 years.

From figure 3, we can find the word government is relates to the word policy. Furthermore, we can find network (links) between money and politics, knowledge and authority. Contrast with the previous analysis in figure 2, in this diagram the word knowledge is relates to word authority as reason of failure in land use and transportation planning. In addition, politics and money appears to have links thus suggest to us the influence of politics in economy factor. 


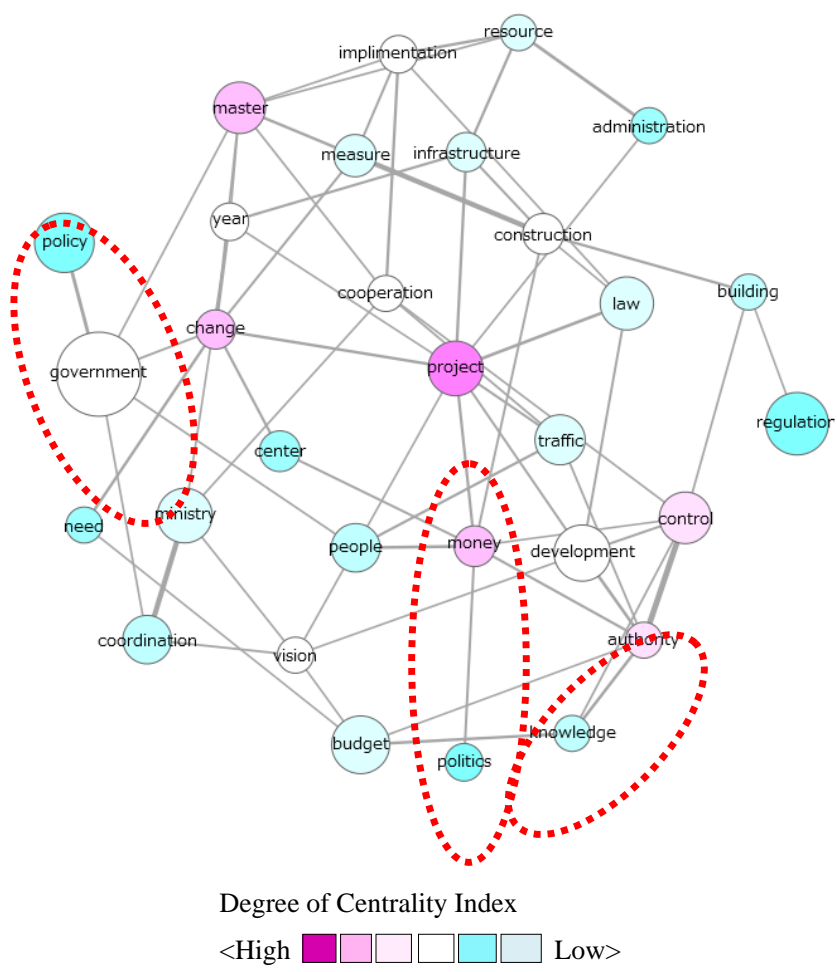

Figure 3: Developing countries with independence 66 years and above.

In general, both analysis result as shown in figures 2 and 3 are similar but not identical. Most of the words appearing in figure 2 also appear in figure 3 . However, the differences between the two diagrams depend on the networks (links) between the words. Based on the analysis, the word "people" does not exist in the highest word frequency in developing countries with lower independence period. In contrast, the word "budget” only appears in developing countries with higher independence period. Thus, suggest to us that from the analysis, factors above can determining land use and transportation planning achievement are varies among developing countries based on independence period. In Table 3, the words appearing in figures 2 and 3 suggest factors determining land use and transportation planning achievement in developing countries based on the degree of centrality analysis result. 
Table 3: Words suggesting the factors determining land use and transportation planning achievement in developing countries.

\begin{tabular}{|c|l|l|}
\hline Independence year & \multicolumn{1}{c|}{$\begin{array}{c}\text { Independence } \\
\text { developing country } \\
\text { less than 65 years }\end{array}$} & $\begin{array}{c}\text { Independence } \\
\text { developing country } \\
\text { more than 66 years }\end{array}$ \\
\hline Words & Ministry & Government \\
\cline { 2 - 3 } $\begin{array}{c}\text { Words are suggesting the } \\
\text { factors determining land } \\
\text { use and transportation } \\
\text { planning achievement in } \\
\text { developing countries. }\end{array}$ & Development & Regulation \\
\cline { 2 - 3 } & Government & Policy \\
\cline { 2 - 3 } & People & Budget \\
\cline { 2 - 3 } & Law & Development \\
\cline { 2 - 3 } & Master & Ministry \\
\cline { 2 - 3 } & Policy & Law \\
\cline { 2 - 3 } & Regulation & Control \\
\cline { 2 - 3 } & Coordination & Master \\
\cline { 2 - 3 } & Traffic & Traffic \\
\hline
\end{tabular}

\section{Summary}

In summary, economy factor is an important factor to provide success of land use and transportation planning. Economy factor gives positive influence to the success and at the same time it also can gives negative influence to failure. However, greater focus given towards country economy achievement leaving the needs of efficient land use and transportation planning is the result of negative influence of economy. As a result of the imbalance and the increase in demands of urban activity and traffic activity, discrepancies like traffic congestion seems a never ending story in developing countries. Throughout the years, it seems that economy growth do not go tally with the success in land use and transportation planning. The demand in urban activity and traffic activity but poor in facility resulted failure in planning. Respondents result analysis in this research proved that there are more factors involved in the failure of land use and transportation planning besides the economy factor. This includes a failure in government factor, political factor, law factor, lack of information, lack of knowledge and also the lack of cooperation among ministries. In principal, result analysis shows that there are differences of word frequency result given by our respondents before and after the world economy crisis in 2007. The crisis affects the kind of answers given by respondents towards their country land use and transportation planning.

Based on the further analysis result, we found that the independence period responsible for differences in the word links between factors of failure in land use and transportation planning. In general, both groups appear to have similar factors of failure in land use and transportation planning but differ in the ties between the words. We found a higher degree of centrality index which means more complex ties (links) of nodes in developing countries with less than 65 years of independence. The differences are telling us that each factor is not the same in each developing country. The relationships between factors are caused 
by different reasons. For example, the lack of knowledge in developing countries less than 65 years of independence seems more associated with people. This describes, more time is needed to educate the people about the important of land use and transportation planning. Each and every single developing country is unique and should not be levelled or put into hierarchy based on economy factors only. Land use and transportation planning should be done locally fitting to the needs and characteristic of each developing country. In order to do this, they should increase the level of knowledge, skill and technology of the local professionals in the country. They should avoid to copycat develop country strategy instead learn from their mistakes and innovate. Integration could only be done if the government plans for integration strategy. As a conclusion, based on the result analysis of this research, we would like to suggest factors of success in land use and transportation planning in developing countries as follows:

a. Government involvement in land use and transportation planning must not be biased towards economy development only but to improve the livelihood of the community.

b. Developing countries must increase public participation as to increase the awareness of the public towards the importance of land use and transportation planning. This will also ease government strategies by increasing knowledgeable community.

c. The number of skill and knowledgeable professionals involved in the policy making especially in the government should be enlarged. The cooperation between urban planning sector and transportation sector should be accordingly formed as to integrate balance in the planning.

Success in economy achievement is not a golden ticket to insure success in land use and transportation planning. Although it is a necessity, economy factor alone could not establish a successful planning. The integration of land use and transportation planning needs economy factor to assist financial needs in providing sufficient infrastructure and also needs methodologies that will work in a variance of history background of developing countries. More data are required in future to investigate in detail the failure of land use and transportation planning in each specific developing country. This is because, each of developing country are different in culture, ethnicity and history background. It is hope that the integration of land use and transportation planning in developing country will continue to spur and balance it with the needs of economy growth.

\section{References}

[1] Deng, X. Private Car Ownership in China: How Important is the Effect of Income?, In Annual Conference of Economist, Hobart, Australia, 2007.

[2] Sarma, Bijon. Dhaka City's Transportation Problem: Is There Any Solution?, Available online http://papers.ssrn.com/sol3/papers.cfm? abstract_id=1476115 at SSRN 1476115, 2009. 
[3] Rodrigue, J. P., Comtois, C., and Slack, B. The geography of transport Systems, Routledge, 2009.

[4] Iyer, L. Direct versus indirect colonial rule in India: Long-term consequences. The Review of Economics and Statistics, 92(4), 693-713, 2010.

[5] Tiwari, G. Towards a sustainable urban transport system: planning for nonmotorized vehicles in cities. Transport and Communications Bulletin for Asia and the Pacific, (68), 49-66, 1999.

[6] Nag, B., Banerjee, S., and Chatterjee, R. Changing features of the automobile industry in Asia: Comparison of production, trade and market structure in selected countries. Asia-Pacific Research and Training Network on Trade, Working Paper Series (37), 2007.

[7] World bank "World Bank Report on China": Building Institutions for Sustainable Urban Transport, 2006, Online at http://www.worldbank.org /transport/transportresults/regions/eap/china-bldg-inst.pdf.

[8] Hook, Walter and Michael Replogle. "Motorization and non-motorized Transport in Asia: Transport System evolution in China, Japan and Indonesia” Land Use Policy 13 no. 1, 69-84, 1996. 